\title{
PEMANFAATAN DAUR ULANG LIMBAH PLASTIK POLYETHYLENE TEREPHTHALATE (PET) SEBAGAI PENGGANTI AGREGAT KASAR PADA BETON
}

\author{
${ }^{1}$ Asrar, ${ }^{1 *}$ Erniati Bachtiar, ${ }^{1}$ Sri Gusty, ${ }^{1}$ Fatmawati Rachim, ${ }^{1}$ Ritnawati, ${ }^{2}$ Arman Setiawan \\ ${ }^{1}$ Program Studi Teknik Sipil Fakultas Teknik Universitas Fajar, Makassar \\ ${ }^{2}$ Program Studi Teknik Sipil Fakultas Teknik Universitas Bosowa, Makassar \\ "korenponden email : erni@ unifa.ac.id
}

\begin{abstract}
ABSTRAK
Sekarang ini material konstruksi beton diarahkan bersifat berkelanjutan dan ramah lingkungan. Banyaknya limbah plastik yang tidak terpakai dan merusak lingkungan. Daur ulang limbah plastik menjadi agregat merupakan salah satu upaya dalam membuat material yang ramah lingkungan. Tujuan penelitian ini adalah untuk mengetahui pengaruh agregat limbah plastik PET (Polyethylene Terephthalate) sebagai pengganti agregat kasar terhadap sifat fisik (slump test, bleeding, segregation, berat isi) dan sifat mekanik kuat tekan beton. Variasi penelitian menggunakan variasi persentase agregat limbah plastik PET (Poyethylene Terephthalate) pada campuran beton sebesar 0\%, 25\%, 50\%, $75 \%$ dan $100 \%$ terhadap volume agregat kasar pada campuran beton. Penambahan persentase agregat limbah plastik PET (Poyethylene Terephthalate) berpengaruh sangat signifikan pada nilai kuat tekan beton, semakin tinggi persentase agregat limbah plasti PET (Poyethylene Terephthalate) maka semakin rendah nilai kuat tekan beton. Menurunnya nilai berat isi, kuat tekan sangat dipengaruhi oleh bertambahnya persentase agregat limbah plastik PET (Poyethylene Terephthalate) pada beton.
\end{abstract}

\section{Kata Kunci: Poyethylene Terephthalate, Beton, Agregat Kasar, Kuat Tekan, Workability}

\begin{abstract}
Now concrete construction materials are directed towards being sustainable and environmentally friendly. The amount of plastic waste that is unused and damages the environment. Recycling plastic waste into aggregate is one of the efforts in making environmentally friendly materials. The purpose of this study was to determine the effect of aggregate PET (Poyethylene Terephthalate) waste as a coarse aggregate substitute for physical properties (slump test, bleeding, segregation, weight) and mechanical properties of compressive strength and concrete tensile strength. Variation of the study used variations in the aggregate percentage of PET plastic waste (Poyethylene Terephthalate) in concrete mixes by $0 \%, 25 \%, 50 \%, 75 \%$ and $100 \%$ against the volume of coarse aggregates in concrete mixtures. The addition of the aggregate percentage of PET (Poyethylene Terephthalate) waste has a very significant effect on the value of concrete compressive strength, the higher the percentage of plastic PET (Poyethylene Terephthalate) waste, the lower the value of concrete compressive strength. The decreasing value of content weight, compressive strength is strongly influenced by the increase in the percentage of aggregate waste PET (Poyethylene Terephthalate) in concrete.
\end{abstract}

\section{Key word: Poyethylene Terephthalate, Concrete, Coarse Aggregate, Compressive Strength, Workability}

\section{PENDAHULUAN}

Perkembangan infrastruktur telah mengalami kemajuan dengan kecepatan yang belum pernah terjadi sebelumnya, terutama dalam pembangunan gedung dan infrastruktur. Keadaan ini telah menimbulkan masalah ketersediaan bahan konstruksi, termasuk bahan baku beton, sehingga menimbulkan 
kekhawatiran kerusakan lingkungan. Agregat kasar merupakan bagian terbesar dari campuran beton, sekitar $65-80 \%$ dari total volume beton. Karena itu, alternatif yang lebih berkelanjutan dari yang agregat kasar alam yang diperlukan. Di sisi lain, perkembangan ekonomi dan perubahan pola konsumsi dan produksi manusia telah menyebabkan peningkatan sampah plastik secara drastis di seluruh dunia. Sampah padat berupa plastik merupakan masalah yang sangat kompleks di perkotaan daerah, termasuk di Indonesia. Data Asosiasi Industri Plastik Indonesia (INAPLAS) dan Badan Pusat Statistik (BPS) menunjukkan sampah plastik di Indonesia mencapai 64 juta ton per tahun per tahun 2019. Jumlah ini diperkirakan terus meningkat dari waktu ke waktu. Akibatnya, peningkatan sampah plastik tidak bisa dihindari, sehingga perlu adanya kebijakan dalam pengelolaan sampah plastik.

Sampah plastik memiliki beberapa ciri, diantaranya bersifat sangat sulit terurai secara alami dan mudah menyerap air. Sifat-sifat sampah plastik ini membuat pembuangan sampah plastik dianggap merusak lingkungan, termasuk degradasi lahan dan lautan serta perubahan iklim, serta mengancam kesehatan manusia. Plastik telah menjadi sampah yang berbahaya dan menantang untuk dikelola. Dampak negatif sampah plastik ternyata sebesar fungsinya (Raju Sharmaa and Prem Pal Bansal, 2016). Plastik membutuhkan waktu sekitar 10-1000 tahun untuk terurai sepenuhnya, yang merupakan durasi yang sangat lama, dan bila terurai, partikel plastik akan mencemari tanah dan air tanah. Saat dibakar, sampah plastik akan menghasilkan asap beracun yang berbahaya bagi kesehatan. Jika proses insinerasi tidak selesai maka plastik akan terurai di udara sebagai dioksin yang sangat berbahaya jika terhirup oleh manusia. Sampah plastik juga menyebabkan banjir karena menyumbat saluran air, dan bendungan sehingga menyebabkan banjir, bahkan kerusakan terparah pada turbin waduk.

Oleh karena itu, dalam keinginan kuat untuk mengurangi sampah plastik, nampaknya akademisi dan peneliti telah mengkaji beberapa potensi daur ulang sampah plastik. Menggunakan kembali sampah plastik dalam beton merupakan cara efektif untuk mengurangi sampah plastik. Terdapat tujuh jenis plastik dengan sifat berbeda, yaitu Polyethylene Terephthalate (PET atau PETE atau Polyester), HighDensity Polyethylene (HDPE), Polyvinyl Chloride (PVC), Low-Density Polyethylene (LDPE), Polypropylene (PP), Polystyrene (PS), dan bioplastik (https://waste4change.com/). Polyethylene terephthalate (PET) merupakan salah satu sampah plastik yang paling melimpah yang umumnya digunakan untuk botol plastik dan kemasan makanan. Dalam penelitian ini dikaji potensi pemanfaatan limbah PET sebagai material beton. Perkembangan teknologi beton semakin populer dengan hadirnya bahan tambahan atau pengganti bahan baku pada campuran beton berupa bahan kimia, fly ash, abu ampas tebu, serat alam, styrofoam, dan polimer.

Ada banyak penelitian tentang bahan pengganti bahan baku beton dengan memanfaatkan limbah industri dan bahan daur ulang. Fly ash merupakan salah satu limbah industri pembangkit listrik yang digunakan sebagai pengganti semen pada campuran beton (Bachtiar. E, 2019, 2020). Selain abu layang, abu sekam padi dapat menggantikan sebagian semen sebagai bahan pengikat pada beton (Ahmad I.A et al, 2014). Beberapa penelitian tentang kantong plastik bekas telah dilakukan (Ghernouti, Y. et al, 2009; Kore, 2019). Penelitian tentang limbah plastik LDPE polietilen densitas rendah(Al-tayeb, M.M et al, 2020), Plastik HDPE (Dewi dan Purnomo 2016) dan penelitian limbah plastik polietilen (Das. S et al, 2016; Jibrael and Peter 2016) sebagai pengganti agregat halus pada beton juga telah dipublikasikan. Pekerjaan penelitian lainnya adalah pada limbah polikarbonat (Mohammed, AS. et al, 2020), dan polipropilen (PP) sebagai pengganti agregat kasar pada beton (Purnomor et al, 2017). Nilai Kuat Tarik Belah Beton Dengan Campuran Limbah Botol Plastik Polyetylene Terephthalate (PET) juga telah dilakukan oleh Armidion dan Rahayu, 2018. Penelitian tentang sampah plastik elektronik sebagai pengganti agregat halus dan kasar juga telah dilakukan (Manjunath ABT, 2016). Terkait pemanfaatan PET sebagai bahan alternatif pembuatan beton, beberapa penelitian telah dihasilkan. Di antara sifat beton yang mengandung PET, kuat tekan dan kuat 
lentur adalah yang paling banyak dipelajari, bersama dengan termal, listrik dan daya tahan, dan sifat lainnya Xuemiao Li et all, 2020). Wiswamitra et all (2020). telah menyelidiki potensi pembuatan beton ringan yang menggunakan agregat pengganti PET yang dikombinasikan dengan mineral berupa abu sekam padi dan semen. Saat membuat beton lebih berpori dengan bantuan PET, penambahan mineral memberikan kuat tekan yang lebih tinggi (Wiswamitra et all, 2020). Basha et al (2020) telah mengembangkan model korelasi antara parameter campuran dan sifat mekanik dan termal beton yang menggunakan agregat plastik daur ulang. Studi ini mengungkapkan potensi mengurangi konduktivitas termal hingga 35-65\% dan memberikan kesempatan untuk menggunakan produk sebagai insulasi termal.

Penelitian ini merupakan penelitian agregat buatan dari plastik sebagai material beton. Penelitian sebelumnya oleh Erniati Bachtiar et al (2020) telah menggunakan agregat buatan dari plastik PET, dimana pada saat pemanasan limbah plastiknya menggunakan titik didih. Untuk paper ini akan membahas nilai slump test, berat volume dan kuat tekan beton yang menggunakan agregat buatan dari plastik yang dipanaskan dengan titik leleh.

\section{METODE PENELITIAN}

Penelitian ini menggunakan metode eksperimental. Penelitian yang dilaksanakan di laboratorium. Variabel penelitian di sini adalah porsi pengganti agregat kasar (daur ulang limbah plastik) pada beberapa variasi porsi campuran beton. Pengujian karakterisasi agregat dan pembuatan sampel beton dilaksanakan pada Laboratorium Struktur dan Bahan Program Studi Teknik Sipil Universitas Fajar Makassar.

\section{Bahan dan Peralatan}

Adapun material penyusun beton yang digunakan adalah semen tipe Portland Cement Composite (PCC), air, agregat kasar/batu pecah (ukuran maksimum $20 \mathrm{~mm}$ ), agregat halus/pasir lokal (ukuran maksimum 4,75) dan Agregat limbah plastik PET (5 mm - 35,4 mm).

Peralatan yang dipakai adalah Universal Testing Machine (UTM), oven, ayakan, mesin los angeles, mesin pencampur bahan (mixer), gelas ukur, cetakan silinder dengan diameter $10 \mathrm{~cm}$ dan tinggi 20 $\mathrm{cm}$, timbangan, , dan peralatan pendukung lainnya.

\section{Mix Desain dan Ekperimental Prosedur}

Pembuatan agregat daur ulang limbah plastik PET, sebelum pemeriksaan karakterisasi agregat dilakukan terlebih dahulu sebelum menghitung mix desain beton dengan berdasarkan standar American Society for Testing and Material (ASTM). Metode yang digunakan dalam desain Beton adalah metode Development of Environment (DOE). Dari hasil hitungan DOE, maka faktor air semen yang digunakan adalah 0,48. Benda uji dibuat dengan variasi campuran dengan 0\%, 25\%, 50\%, 75\% dan $100 \%$ agregat limbah plastik PET dari jumlah agregat kasar. Masing-masing sampel dibuat 3 buah variasi campuran dimana 3 buah untuk pengujian kuat tekan. Jadi Jumlah sampel keseluruhan 30 buah sampel. Sampel dibuat dengan menggunakan cetakan silinder ukuran $10 \mathrm{~mm}$ x $20 \mathrm{~mm}$. Untuk setiap variasi sampel diberi nama yakni untuk 0\% agregat limbah plastik PET $=$ PET, 25\% agregat limbah plastik PET $=$ PET-25, 50\% agregat limbah plastik PET $=$ PET-50, 75\% agregat limbah plastik PET $=$ PET-75, 100\% agregat limbah plastik PET = PET-100.

Dari komposisi yang digunakan adalah hasil mix design. Pencampuran material penyusun beton menggunakan alat mixer. Sebelum beton dituang dalam cetakan silinder (dalam kondisi beton segar), terlebih dahulu dilakukan pengujian sifat fisik beton segar yakni slump test, bleeding, segregasi dan 
berat volume beton. Benda uji dibuka dari cetakan setelah benda uji mengeras sekitar minimal $4-5$ jam dari waktu beton dicetak. Benda uji yang telah dibuka dari cetakan kemudian dilakukan curing sebagai perawatan beton dengan cara benda uji beton tersebut direndam dalam bak air selama 28 hari. Setelah itu dikeluarkan dari bak air kemudian di diamkan kurang lebih 20 jam berdasarkan SNI 032493. Pengujian kuat tekan dilakukan pada beton berumur 28 hari. Pengujian kuat tekan berdasarkan ASTM C39/C39M -12a. dari hasil kuat telakan dilakukan rekapitulasi dan kemudian analisis hubungan dengan persentase agregat limbah plastik dengan kuat tekan yang dihasilkan.

\section{HASIL \& PEMBAHASAN}

\section{Agregat Halus dan Kasar}

Pengujian karakteristik agregat halus dan kasar dilakukan dilaboratorium Program Studi Teknik Sipil Universitas Fajar Makassar berdasarkan standar American Society for Testing and Material (ASTM). Pengujian ini dilakukan untuk mengetahui kualitas dari agregat serta apakah agregat tersebut layak digunakan atau tidak sebagai material penyusun beton. Hasil pengujian material agregat diperoleh karakteristik agregat halus dan agregat kasar telah memenuhi kriteria sebagai material penyusun beton. Hasil pengujian agregat halus (pasir), agregat kasar (batu pecah) dapat dilihat berturut-turut pada Tabel 1; Tabel 2

Tabel 1. Hasil Pemeriksaan Karakteristik Agregat Halus (Pasir)

\begin{tabular}{|c|l|c|}
\hline No & \multicolumn{1}{|c|}{ Jenis Pengujian } & Hasil Pengujian Agregat Halus \\
\hline 1 & Kadar Lumpur & $4,5 \%$ \\
2 & Kadar Air & $4,71 \%$ \\
3 & Berat Volume & \\
& a. Kondisi Lepas & 1,42 \\
& b. Kondisi Padat & 1,60 \\
4 & Absorpsi & $2,04 \%$ \\
5 & Berat Jenis & \\
& a. Bj. Nyata & 2,58 \\
& b. Bj. Dasar Kering & 2,45 \\
& c. Bj. Kering Permukaan & 2,50 \\
6 & Modulus Kehalusan & 2,77 \\
7 & Kadar Organik & No. 2 \\
\hline
\end{tabular}


Tabel 2. Hasil Pemeriksaan Karakteristik Agregat Kasar (Batu Pecah)

\begin{tabular}{|c|l|c|}
\hline & & \\
No & \multicolumn{1}{|c|}{ Jenis Pengujian } & Hasil Pengujian Agregat Kasar \\
& & \\
\hline 1 & & Kadar Lumpur \\
2 & Kadar Air & $0,75 \%$ \\
3 & Berat Volume & $1,78 \%$ \\
& a. Kondisi Lepas & 1,66 \\
& b. Kondisi Padat & 1,74 \\
4 & Absorpsi & $1,56 \%$ \\
5 & Berat Jenis & 2,85 \\
& a. Bj. Nyata & 2,73 \\
& b. Bj. Dasar Kering & 2,77 \\
& c. Bj. Kering Permukaan & 6,64 \\
7 & Modulus Kehalusan & $18,67 \%$ \\
\hline
\end{tabular}

\section{Slump Test, Bleeding dan segregasi}

Workability/Kelacakan adukan beton dapat dilihat dengan melihat nilai slump test. Kemudahan pengerjaan beton tergantung dari kelecakan adukan beton. Ukuran dari tingkat kemudahan adukan pada saat diaduk, diangkut, dan dituang serta dipadatkan tanpa menimbulkan pemisahan kerikil (segregation) serta naiknya air kepermukaan (bleeding). Komposisi campuran, kondisi fisik dan jenis bahan pencampurnya mempengaruhi tingkat kelecakan. Adapun hasil pPengujian slump test dapat dilihat pada Tabel 3 .

Tabel 3. Hasil Pengukuran Nilai Slump

\begin{tabular}{|c|c|c|c|c|}
\hline No & $\begin{array}{c}\text { Varisasi } \\
\text { Campuran (\%) }\end{array}$ & $\begin{array}{c}\text { Test Slump1 } \\
(\mathrm{cm})\end{array}$ & $\begin{array}{c}\text { Test Slump 2 } \\
(\mathrm{cm})\end{array}$ & $\begin{array}{c}\text { Nilai Rata-Rata } \\
(\mathrm{cm})\end{array}$ \\
\hline 1 & 0 & 9,2 & 8,9 & 9,2 \\
2 & 25 & 8,6 & 8,2 & 8,4 \\
3 & 50 & 7,8 & 8,0 & 7,9 \\
4 & 75 & 6,7 & 6,2 & 6,45 \\
5 & 100 & 6,1 & 5.7 & 6,1 \\
\hline
\end{tabular}

Tabel 3 terlihat bahwa nilai slump untuk beton normal maupun beton dengan campuran agregat limbah plastik PET memenuhi syarat standar slump yakni 6-18 $\mathrm{cm}$. terlihat bahwa adukan beton memiliki workability yang baik, dengan kata lain bahwa kemudahan dalam pencampuran baik. Dari hasil pengujian slump test ini juga menunjukkan adukan campuran beton telah tercampur dengan merata dan sempurna dan terlihat tidak terjadi segregasi (pemisahan kerikil) dan bleeding (naiknya air kepermukaan) pada adukan beton segar. 


\section{Berat Volume Beton}

Sebelum dilakukan pengujian kuat tekan, pengambilan data nilai berat satuan beton dilakukan pada saat beton berumur 28 hari. Hasil rata-rata berat volume beton yang menggunakan limbah agregat plastik dapat dilihat pada Tabel 4.

Tabel 4. Hasil Pengujian Berat Volume Beton

\begin{tabular}{|c|c|c|}
\hline $\begin{array}{c}\text { Variasi Campuran } \\
(\%)\end{array}$ & $\begin{array}{c}\text { Satuan berat rata rata Beton } \\
\left(\mathrm{kg} / \mathrm{m}^{3}\right)\end{array}$ & $\begin{array}{c}\text { Reduksi } \\
(\%)\end{array}$ \\
\hline 0 & $2,339.70$ & 0 \\
25 & $2,325.42$ & 0.61 \\
50 & $2,116.24$ & 9.55 \\
75 & $1,730.36$ & 26.04 \\
100 & $1,549.36$ & 33.78 \\
\hline
\end{tabular}

Tabel 4 terlihat bahwa hasil reduksi dengan pengganti daur ulang limbah plastik PET sebagai agregat kasar, semakin tinggi persentase daur ulang limbah plastik PET semakin tinggi reduksinya terhadap berat volume beton. Dengan kata lain semakin tinggi persentase daur ulang limbah plastik PET maka semakin kecil berat volume beton. Dari hasil pengujian berat volume $100 \%$ daur ulang limbah plastik PET memenuhi syarat sebagai beton ringan yakni $1,549.36<1900 \mathrm{~kg} / \mathrm{m}^{3}$. Dengan berat isi berkisar antara $(1400-1800 \mathrm{~kg} / \mathrm{m} 3)$, namun kuat tekan beton tidak memenuhi syarat untuk digunakan sebagaimana beton normal dengan kuat tekan antara 7 MPa sampai 17 MPa (Tjokrodimuljo, 2009).

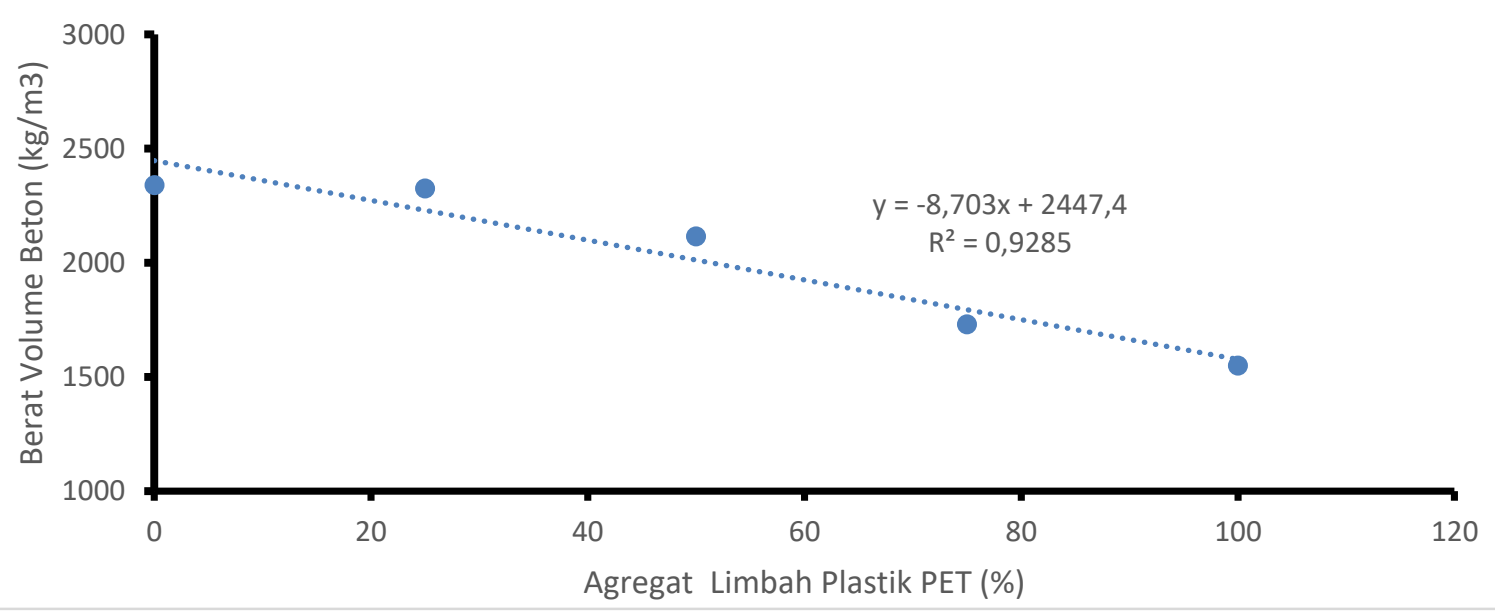

Gambar 1. Hubungan Antara Berat Volume Beton Dengan Persentase Penambahan Agregat Limbah Plastik PET.

Gambar 1 memperlihatkan hubungan jumlah agregat limbah plastik PET dengan persentase reduksi berat volume beton, terlihat semakin tinggi hasil persaman linear $\mathrm{R}^{2}=0,928$ dengan nilai koefisen korelasi $\mathrm{R}=0,963$ mendakati 1 maka disimpulkan bahwa jumlah agregat plastik sangant mempengaruhi berat volume beton. Hubungna jumhlah agregat limbah plastik PET dengan berat volume beton sangant signipikan. 


\section{Kuat Tekan}

Kuat tekan beton diperoleh dari kemampuan menahan tekan maksimum yang dapat dipikul beton persatuan luas. Kuat tekan beton atau dikenal tegangan tekan maksimum $\sigma$ dengan satuan $\mathrm{N} / \mathrm{mm}^{2}$ (MPa). Secara umum, kuat tekan beton dipengaruhi oleh beberapa faktor. Faktor-faktor tersebut antara lain sifat dan jenis semen, sifat dan jenis agregat,rasio air semen (FAS), kelecakan (workability), jenis campuran, perawatan (curing) beton dan umur beton. Yang paling mempengaruhi kekuatan beton adalah Faktor air semen (FAS) dimana semakin kecil FASnya nilai kuat tekan semakin besar (Erniati $\&$ M. Wihardi Tjaronge, 2016). Pengujian kuat tekan beton pada umur 28 dapat dilihat berturut-turut pada Tabel 5.

Tabel 5. Hasil Pengujian Kuat tekan

\begin{tabular}{|c|c|c|}
\hline \multirow{2}{*}{ No } & \multirow{2}{*}{ Nama Sampel } & Nilai rata-rata (Mpa) \\
\cline { 3 - 3 } & & Kuat Tekan \\
\hline 1 & BN & 17,38 \\
\hline 2 & PET-25\% & 15,58 \\
\hline 3 & PET-50\% & 14,23 \\
\hline 4 & PET-75\% & 12,50 \\
\hline 5 & PET-100\% & 10,55 \\
\hline
\end{tabular}

Tabel 5 memperlihatkan hasil nilai rata-rata kuat tekan beton normal BN sebagai pembanding diperoleh kuat tekan sebesar 17,38 MPa. Pada penelitian ini sesuai nilai kuat tekan pada beton dengan $0 \%$ agregat limbah plastik PET dibawah target yang direncanakan yaitu $20 \mathrm{MPa}$. Jadi penambahan persentase agregat limbah plastik PET berpengaruh sangat signifikan pada nilai kuat tekan beton dimana semakin tinggi persentase penambahan agregat limbah plasti PET maka semakin rendah nilai kuat tekan beton.

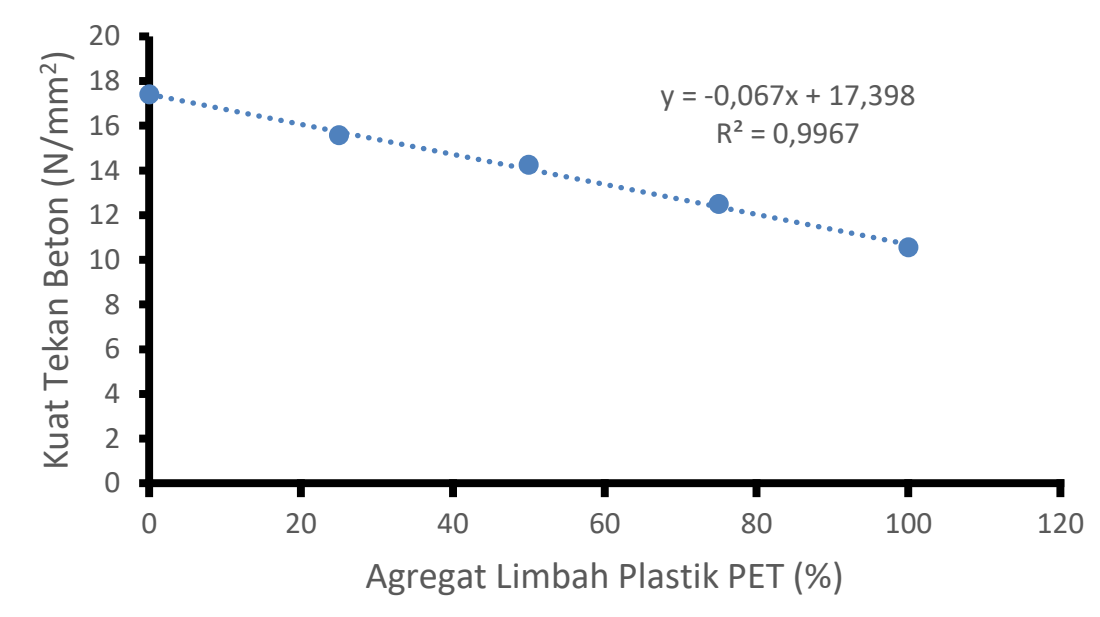

Gambar 2. Hubungan kuat tekan dengan persentase agregat limbah plastik PET dalam beton

Gambar 2 memperlihatkan hubungan regresi jumlah agregat limbah plastik PET dengan persentase kuat tekan beton, terlihat semakin tinggi hasil persaman linear linear $\mathrm{y}=-0,067 \mathrm{x}+17,39$ koefisien determinasi $\mathrm{R}^{2}=0,996$ jadi nilai koefisen korelasi $\mathrm{R}=0,998$ maka dapat disimpulkan bahwa jumlah penambahan agregat limbah plastik PET sangat mempengaruhi kuat tekan beton.. 


\section{Kesimpulan}

\section{PENUTUP}

Desain pencampuran beton dengan menggunakan semen PCC, batu pecah dengan ukuran maksimum $20 \mathrm{~mm}$, faktor air semen $=0,48$ menghasilkan beton segar dengan Nilai slump semakin menurun seiring dengan penambahan jumlah agregat limbah plastik. Perubahan berat volume beton dipengaruhi oleh besarnya penambahan agregat limbah plastik PET, jadi semakin tinggi penambahan semakin rendah berat volume beton. Untuk beton dengan variasi $0 \%, 25 \%, 50 \%, 75 \%, 100 \%$ memiliki berat volume berturut-turut sebesar 2339,70 kg/m3;2325,42 kg/m3;2116,24 kg/m3; 1730,36 kg/m3; $1549,36 \mathrm{~kg} / \mathrm{m} 3$. Hubungan antara persentase pengaruh daur ulang limbah plastik PET sebagai agregat kasar terhadap kuat tekan adalah sangant signifikan, semakin tinggi penambahan agregat limbah plastik PET maka nilai kuat tekan semakin kecil.

\section{DAFTAR PUSTAKA}

1. ASTM C.125-1995:61 "Standard Defenition of Technolgi Relating to concrete and Concrete Agregates, Annual Book of ASTM Standards, USA.

2. ASTM C29M-97. " Examination Heavy Volume”, Annual Books of ASTM Standards, USA.

3. ASTM C566-97. "Examination Levels of Waters Content". Annual Books of ASTM Standards, USA.

4. ASTM C117-95. "Examination Levels of Mud". Annual Books of ASTM Standards, USA.

5. ASTM C40-99."'Examination Levels of Organic", Annual Books of ASTM standards, USA.

6. ASTM C40-99."Examination Abrasion/Wear", Annual Books of ASTM standards, USA.

7. ASTM C39/39M-12a, standard Test Method for Compressive Strength of Cylindrical Concrete Specimens, October 2012.

8. Ahmad. IA et al. 'Durability of Concrete Using Rice Husk Ash as Cement Substitution Exposed To Acid Rain', International Journal of Engineering Research and Applications, 4(5), (2014) pp. 144-149.

9. Armidion, R dan Rahayu, T (2018) : Peningkatan Nilai Kuat Tarik Belah Beton Dengan Campuran Limbah Botol Plastik Polyetylene Terephthalate (PET), Jurnal Konstruksia, Volume 10 Nomer 1, Teknik Sipil Universitas Muhammadiyah Jakarta, Jakarta.

10. Al-tayeb, M.M., Daoor, I., and Zeyad, AM. "Effect of Partial Replacements of Coarse Aggregate by Polycarbonate Plastic Waste on the First Crack Impact Resistance of Concrete Beam”, Journal of Environment and Earth Science, March. 2020), doi: 10.7176/jees/10-2-06.

11. Das, S., Alam, MT., and Chowdhury, I. "Utilization of plastic Waste In Concrete as Partial Replacement of Fine Aggregate." Proceedings of 3rd International Conference on Advances in Civil Engineering. Chittagog. Bangladesh, 2016

12. Dewi, U.S, dan Purnomo, R (2016) : Pengaruh Tambahan Limbah Plastik HDPE (high density polyethylene) Terhadap Kuat Tekan Beton Pada Mutu k.125, Jurnal, Tapak Vol. 6, Teknik Sipil Universitas Muhammadiyah Metro, Lampung.

13. Jibrael, MA. and Peter, F. "Strength and Behavior of Concrete Contains Waste Plastic", Journal of Ecosystem \& Ecography, 6(2), 2016 pp. 4-7. DOI:10.4172/2157-7625.1000186.

14. Erniati dan M. Wihardi Tjaronge (2016) : Mikrostruktur Self Compacting Concrete, Penerbit Leutika Prio, Yogyakarta.

15. Istimawan Dipohusodo, 1994, Struktur Beton Bertulang, berdasarkan SK SNI T-15-1991-03 Departemen Pekerjaan Umum RI, Jakarta, Gramedia Pustaka Utama.

16. Bachtiar. E. "Environmentally Friendly Material". Faculty of Engineering, Fajar University \& Tohar Media, Makassar, 2019. 
17. Bachtiar. E "The connection between oven curing duration and compressive strength on C-type fly ash based-Geopolymer mortar", ARPN Journal of Engineering and Applied Sciences, 2020, 15(5), pp. 1-6.

18. Basha S.I., M.R. Ali, S.U. Al-Dulaijan, M. Maslehuddin. "Mechanical and thermal properties of lightweight recycled plastic aggregate concrete". Journal of Building Engineering 32 (2020) 101710 DOI:10.1016/j.jobe.2020.101710

19. Erniati Bachtiar, Mustaaan et al (2020) Examining Polyethylene Terephthalate (PET) as Artificial Coarse Aggregates in Concrete, Civil Engineering Journal, Vol 6 No. 12, Desember 2020, DOI:10.28991/cej-2020-03091626

20. Ghernouti, Y. et al. 'Use of Recycled Plastic Bag Waste In The Concrete', Journal of International Scientific Publications: Materials, Methods and Technologies, 2009 pp. 480-487

21. Kore, S.D. 'Feasibility Study on Use of Plastic Waste as Fine Aggregate in Concrete Mixes', Journal of Building Material Science, 1(1), 2019, pp. 26-31. DOI:10.30564/jbmr.v1i1.1204

22. Manjunath, ABT. "Partial Replacement of E-plastic Waste as Coarse-Aggregate in Concrete". Procedia Environmental Sciences. 35 (20160. pp. 731-739. DOI:10.1016/j.proenv.2016.07.079

23. Mohammed, AS. et al. "Mechanical Properties of Concrete and Mortar Containing Low Density Polyethylene Waste Particles as Fine Aggregate.”. Journal of Materials and Engineering Structures, 7. February 2020 pp. 57-72.

24. Purnomo H., Pamudji, G., and M. Satim. "Influence of uncoated and coated plastic waste coarse aggregates to concrete compressive strength". MATEC Web of Conferences, 101, 2017, DOI: 10.1051/matecconf/201710101016.

25. Raju Sharmaa, Prem Pal Bansal. Use of different forms of waste plastic in concrete - a review. Journal of Cleaner Production. Volume 112, Part 1, Pages 473-482, 20 January 2016. DOI: 10.1016/j.jclepro.2015.08.042

26. SNI 02-6820-2002 : Spesifikasi Agregat Halus, Badan Standarisasi Nasional, Departemen Pekerjaan Umum, 2002.

27. SNI-03-2847-2002 : Spesifikasi Persyaratan Air dalam pasal 5.4 ayat 1 s/d 3, Badan Standarisasi Nasional, Departemen Pekerjaan Umum, 2002.

28. SNI 15-7064-2004: Spesifikasi Agregat Halus, Badan Standarisasi Nasional, Departemen Pekerjaan Umum, 2004.

29. SNI 03-3449-2002 : Mengenai Tata Cara Pembuatan Campuran Beton Ringan Dengan Agregat Ringan, Departemen Pekerjaan Umum, 2002.

30. SNI 03-2847-2002 : Tata Cara Perhitungan Struktur Beton untuk Bangunan Gedung, Departemen Pekerjaan Umum, 2002.

31. SNI 03-6468-2000. Tata Cara Perencanaan Campuran Tinggi degan Semen Portland dengan Abu Terbang. Badan Standarisasi Nasional. Departemen Pekerjaan Umum, 2002.

32. Tri, Mulyono (2006) : Teknologi Beton, Penerbit ANDI, Yogyakarta.

33. Tjokrodimuljo, Kardiyono (2009): Teknologi Beton, Biro Penerbit Teknik Sipil Universitas

34. Wiswamitra K.A, Dewi S.M., Choiron M.A., Wibowo A. "The Effect of Adding Minerals on Plastic Aggregate to Lightweight". Concrete IOP Conf. Ser.: Earth Environ. Sci. 506012046 (2020)

35. Xuemiao Li, Tung-Chai Ling, Kim Hung Mo. "Functions and impacts of plastic/rubber wastes as eco-friendly aggregate in concrete - A review", Construction and Building Materials 240 (2020) 117869 DOI:10.1016/j.conbuildmat.2019.117869 